\title{
Consideration of torsional irregularity in Modal Response Spectrum Analysis
}

\author{
O. A. Mohamed \& O. A. Abbass \\ Department of Civil Engineering, Abu Dhabi University, UAE
}

\begin{abstract}
Modal Response Spectrum Analysis (MRSA) is one of the most commonly used methods for determination of seismic response in building structures. In MRSA, the structure is idealized as a series of single-degree-of-freedom systems, each having its own mode shape and vibration period. MRSA is permitted for structures in any seismic design category (SDC) and many types of irregularities. Even the most traditional structures can have torsional irregularity types $1 a$ or $1 b$ as defined in ASCE 7-10. The presence of torsional irregularities implies seismic forces may be amplified due to eccentricity of seismic forces. The purpose of this paper is the discuss the determination of the effects of torsional irregularity on seismic response in accordance with ASCE 7-10, when MRSA is used for calculation of seismic forces and drifts. A common misconception is that use of MRSA incorporates different vibration modes, therefore, torsional irregularity effects need not be accounted for as many vibration modes already include twisting of the three-dimensional structure. This paper discusses why torsional irregularity must be accounted for, even when MRSA is used. A case study reinforced concrete structure is used to demonstrate an interpretation of the current code provisions for incorporation of torsional irregularity effects when MRSA method is used.
\end{abstract}

Keywords: Modal Response Spectrum Analysis, Equivalent Lateral Force Analysis, torsional irregularity.

\section{Introduction}

The Modal Response Spectrum Analysis (MRSA) procedure for seismic analysis and design is described in section 12.9 of ASCE 7-10 [1]. MRSA is popular as the method provides a more realistic assessment of structural demand under the 
Maximum Considered Earthquake (MCER), compared to the generally more conservative Equivalent Lateral Force (ELF) method. MRSA is permitted for a much wider range of structures with various irregularities, building heights. MRSA is also permitted for buildings in most seismic design categories (SDC). Horizontal torsional irregularity may affect structures with rigid or semi-rigid diaphragms leading to amplification of the structural response when seismic forces are applied eccentrically, with respect to the floor center of rigidity. Torsional irregularity concerns were addressed in various Federal Emergency Management Agency (FEMA) publications as described by Mohamed and Khamwan [2]. A floor in a structure is said to have horizontal torsional irregularity of type $1 a$ if the maximum story drift, $\delta_{A}$ under seismic forces including accidental torsion at one end of the structure exceeds 1.2 times the average, $\delta_{a v g}$, of the story drift at the two ends of the structure (as shown in fig. 1). Extreme horizontal torsional irregularity of type $1 b$ is said to exist if $\delta_{A}$ exceeds 1.4 times $\delta_{\text {avg }}$. Structural response increases when floors or diaphragms are torsional irregular. Such magnified effects, if not accounted for, can lead to structural failures. This paper addresses ASCE 7-10 [1] recommendations for consideration of accidental torsion in seismic response of the structure.

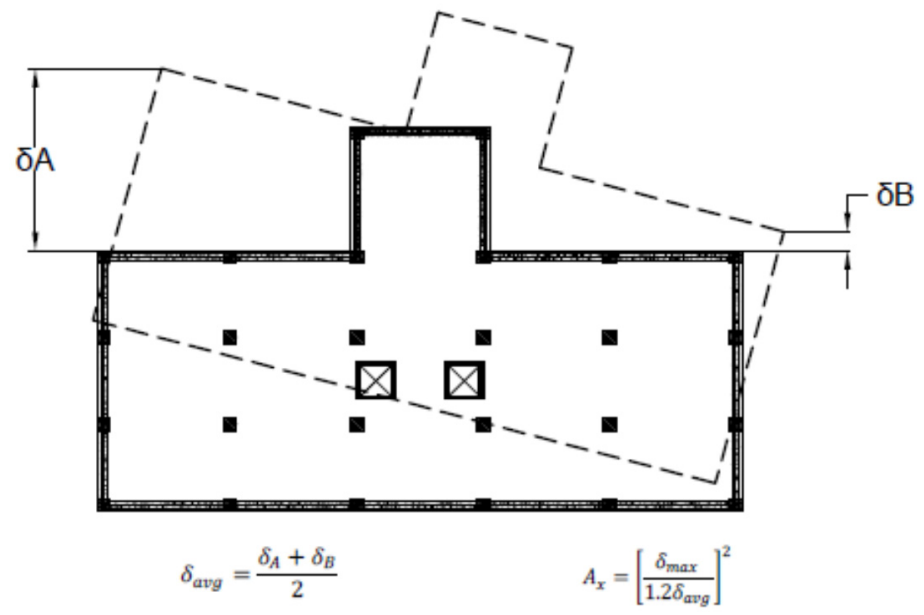

Figure 1: Definition of amplification factor.

\section{Amplification of accidental torsional moments}

It is known that MRSA is a dynamic analysis method that considers inherent torsion. However, additional forces and deformations may result from the accidental application of seismic forces at an eccentricity with respect to the center of mass of the diaphragm. The additional accidental torsional moments, $M_{t a}$, is accounted by computationally by assuming that the center of 
mass is displaced from its location by $5 \%$ of the dimension of the structure perpendicular to the direction of the applied load.

Structures affected by torsional irregularity type $1 \mathrm{a}$ or $1 \mathrm{~b}$ must have the effects of irregularity on torsional moment accounted for by multiplying the accidental torsional moments, $M_{t a}$, by an amplification factor $A_{x}$. ASCE 7 [1] section 12.8.4.3 defines the amplification factor as:

$$
A_{x}=\left(\frac{\delta_{\max }}{1.2 \delta_{a v g}}\right)
$$

If amplified torsional moments due to torsional irregularities are not considered in the design, additional forces may be generated leading to structural failures and/or larger deformations leading to pounding of buildings [3]. The limitations of MRSA and other methods of seismic design are discussed by Mohamed [4].

\section{Case study}

In order to demonstrate the source and significance of torsional irregularity, a flat slab with perimeter beams case study office building shown in fig. 2 was designed analysed and designed in accordance with the International Building Code (IBC) [5]. Building and site data is summarized in Table 1. Concrete strength is taken as $50 \mathrm{MPa}$ for all structural elements, for simplicity, and the building is assumed to be in site class $\mathrm{C}$. Using the seismic parameters in Table 1 and assuming risk category II, the structure is classified to fall under SDC D, per sect 11.6 of ASCE 7 [1].

The lateral force resisting system is a dual system of special reinforced concrete moment resisting frame and special reinforced concrete shear wall, as permitted by section 12.2 of ASCE 7 [1]. The deflection amplification factor is $C_{d}=5.5$.

Table 1: $\quad$ Building geometry, material properties, and MCER data.

\begin{tabular}{|l|l|}
\hline \multicolumn{1}{|c|}{$\begin{array}{c}\text { Dimensions of structural } \\
\text { elements (mm) }\end{array}$} & $\begin{array}{c}\text { Response spectral } \\
\text { acceleration and } \\
\text { design parameters }\end{array}$ \\
\hline Beams: $600 \times 800$ & $\mathrm{~S}_{\mathrm{s}}=1.65$ \\
Columns: $800 \times 800$ & $\mathrm{~S}_{1}=0.68$ \\
Slab thickness: $300 \mathrm{~mm}$ & $\mathrm{~S}_{\mathrm{DS}}=1.1$ \\
Shear wall thickness: $250 \mathrm{~mm}$ & $\mathrm{~S}_{\mathrm{D} 1}=0.589$ \\
& $\mathrm{~T}_{\mathrm{L}}=8$ \\
\hline
\end{tabular}




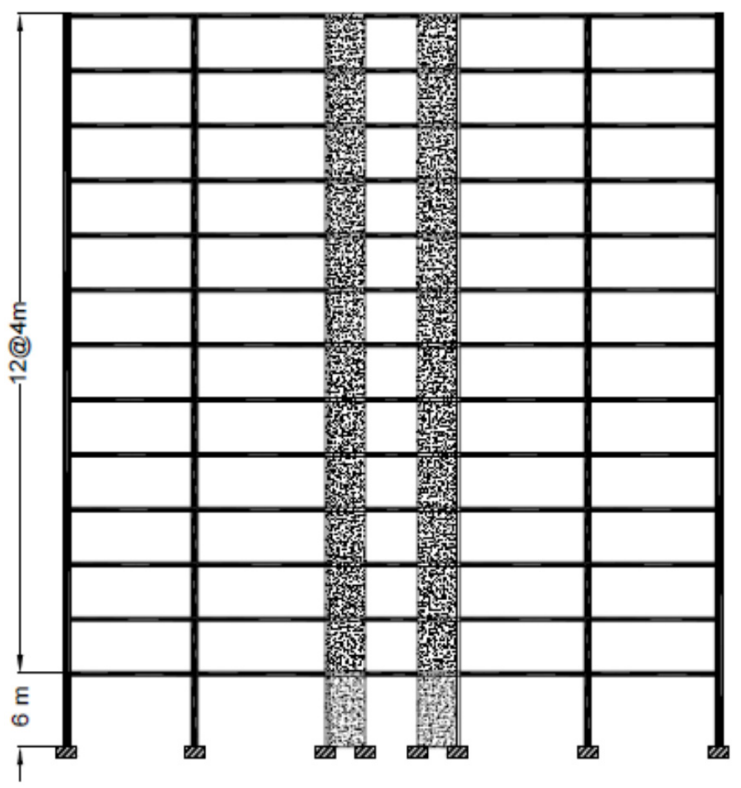

(a)

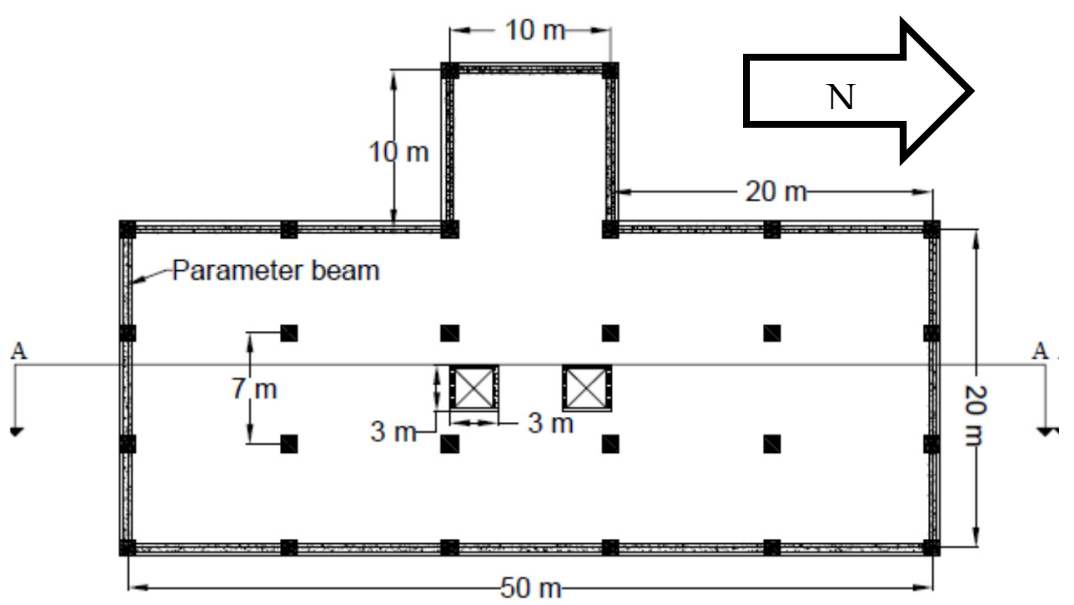

(b)

Figure 2: (a) Building elevation showing shear wall for lateral force resistance; (b) Building plan view showing one dimension longer than the other. 
The response spectrum for the case study is shown in fig. 3 .

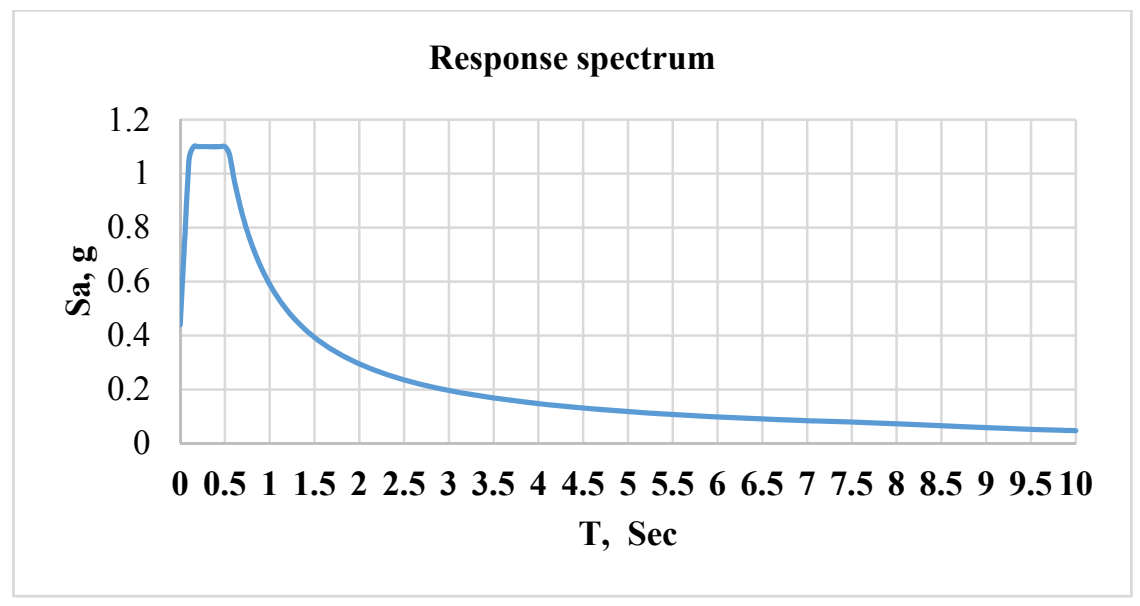

Figure 3: Response spectrum for case study.

\subsection{Shear walls near floor center of mass}

This section addresses torsional irregularity in the building plan shown in fig.2b. The plan view does not appear to contain torsional irregularities. Drifts calculated and shown in Table 2 indicate that torsional irregularity does not exist in the North-South direction for any story. This is because the maximum story drift is less than $1.2 \mathrm{x}$ the average story drift.

Table 2: $\quad$ Story drift and seismic irregularity for seismic force in the NorthSouth direction.

\begin{tabular}{|c|c|c|c|c|}
\hline Story & $\begin{array}{c}\text { Drift at A } \\
\text { (see fig. 1) }\end{array}$ & $\begin{array}{c}\text { Drift at B } \\
\text { (see fig. 1) }\end{array}$ & Max. drift & $\begin{array}{c}\text { Max. drift/1.2 x } \\
\text { avg. drift }\end{array}$ \\
\hline 13 & 0.00151 & 0.001415 & 0.001507 & 1.0315 \\
\hline 12 & 0.00176 & 0.001592 & 0.001755 & 1.0487 \\
\hline 11 & 0.00203 & 0.001798 & 0.002029 & 1.0604 \\
\hline 10 & 0.00231 & 0.002015 & 0.002305 & 1.0671 \\
\hline 9 & 0.00256 & 0.002214 & 0.002553 & 1.0711 \\
\hline 8 & 0.00276 & 0.002376 & 0.002755 & 1.0738 \\
\hline 7 & 0.00290 & 0.002487 & 0.002897 & 1.0762 \\
\hline 6 & 0.00297 & 0.002532 & 0.002967 & 1.0791 \\
\hline 5 & 0.00295 & 0.002494 & 0.00295 & 1.0838 \\
\hline 4 & 0.002824 & 0.002352 & 0.002824 & 1.0912 \\
\hline 3 & 0.002557 & 0.002072 & 0.002557 & 1.1048 \\
\hline 2 & 0.00209 & 0.001596 & 0.00209 & 1.1340 \\
\hline
\end{tabular}


The drifts in each story when the seismic force is applied in the East-West direction are shown in Table 3 . The last column of Table 3 shows that torsional irregularity of type $1 a$ exists for all stories up to the $10^{\text {th }}$ story.

Table 3: Story drift and seismic irregularity for seismic force in the EastWest direction.

\begin{tabular}{|c|c|c|c|c|}
\hline Story & $\begin{array}{c}\text { Drift at A } \\
\text { (see fig. 1) }\end{array}$ & $\begin{array}{c}\text { Drift at B } \\
\text { (see fig. 1) }\end{array}$ & Max. drift & $\begin{array}{c}\text { Max. drift/1.2 } \\
\text { x avg. drift }\end{array}$ \\
\hline 13 & 0.001768 & 0.0014 & 0.001768 & 1.115105645 \\
\hline 12 & 0.002042 & 0.0015 & 0.002042 & 1.151071026 \\
\hline 11 & 0.002318 & 0.0016 & 0.002318 & 1.181146497 \\
\hline 10 & 0.002586 & 0.0017 & 0.002586 & 1.20223152 \\
\hline 9 & 0.002817 & 0.00181 & 0.002817 & 1.217109527 \\
\hline 8 & 0.002999 & 0.0019 & 0.002999 & 1.229098361 \\
\hline 7 & 0.003119 & 0.0019 & 0.003119 & 1.240159046 \\
\hline 6 & 0.003169 & 0.0019 & 0.003169 & 1.252074279 \\
\hline 5 & 0.003137 & 0.0018 & 0.003137 & 1.267218744 \\
\hline 4 & 0.003008 & 0.00166 & 0.003008 & 1.289050782 \\
\hline 3 & 0.002754 & 0.00141 & 0.002754 & 1.32340221 \\
\hline 2 & 0.00233 & 0.001014 & 0.002331 & 1.393721973 \\
\hline
\end{tabular}

The torsional irregularity evidenced by the results in Table 3 is due to the larger twisting moment as a result of the seismic forces acting on a larger eccentricity. It therefore anticipated that under seismic forces in the East-West direction accidental torsion would be amplified due to torsional irregularity. Using Eq. (1) and story displacements in the East-West direction, the amplification factor for accidental torsion can be calculated as shown in Table 4.

Amplification factors for accidental torsion, $\mathrm{A}_{\mathrm{x}}$, are now known for each story affected by torsional irregularity. MRSA accounts for the effects of accidental torsion, unlike the Equivalent Lateral Force (ELF) method described in section 12.8 of ASCE 7 [1]. However, amplification of torsion effects due to irregularity is required even when Modal Response Spectrum Analysis is used. In order to assess the result of the magnification of accidental torsion, story displacements due to seismic forces in the East-West direction are calculated using Eq. (2) and results are summarized in Table 5. This method of calculating lateral deflection is specified in section 12.8.6 of ASCE 7 [1].

$$
\delta_{x}=\frac{C_{d} \delta_{x e}}{I_{e}}
$$

where

$C_{d}$ : Deflection amplification factor. 
$\delta_{x e}:$ The deflection at specified location from elastic analysis.

$I_{e}:$ The importance factor.

Table 4: Amplification factor for accidental torsion moment in the East-West direction.

\begin{tabular}{|c|c|c|c|c|}
\hline Story & $\begin{array}{c}\text { Maximum } \\
\text { displacement } \\
\text { mm }\end{array}$ & $\begin{array}{c}\text { Average } \\
\text { displacement } \\
\text { mm }\end{array}$ & $\begin{array}{c}\text { Maximum } \\
\text { displacement/average } \\
\text { displacement }\end{array}$ & $\begin{array}{c}\text { Amplification } \\
\text { factor, Ax }\end{array}$ \\
\hline 13 & 135.5 & 108.1 & 1.253381 & 1.090947 \\
\hline 12 & 128.4 & 101.7 & 1.262122 & 1.106217 \\
\hline 11 & 120.3 & 94.7 & 1.270614 & 1.121153 \\
\hline 10 & 111 & 86.8 & 1.278953 & 1.135917 \\
\hline 9 & 100.7 & 78.2 & 1.287759 & 1.151613 \\
\hline 8 & 89.5 & 68.9 & 1.297699 & 1.16946 \\
\hline 7 & 77.5 & 59.2 & 1.309607 & 1.191021 \\
\hline 6 & 65.1 & 49.1 & 1.324625 & 1.218494 \\
\hline 5 & 52.4 & 39 & 1.344505 & 1.255343 \\
\hline 4 & 39.9 & 29.1 & 1.372261 & 1.307709 \\
\hline 3 & 27.9 & 19.8 & 1.413723 & 1.387926 \\
\hline 2 & 17 & 11.4 & 1.483029 & 1.527344 \\
\hline 1 & 7.7 & 4.8 & 1.617366 & 1.816578 \\
\hline
\end{tabular}

Table 5 shows that the effect of amplified torsion on structural drift is significant and therefore must always be considered.

\subsection{Shear walls furthest from the floor center of mass}

Alternative to calculating the amplified responses caused by torsional irregularity, it is often possible to counter accidental torsion by providing stiffer lateral force resisting system that can provide resistance to story deformations torsional deformations. The shear walls shown in fig. 4 are added in the EastWest direction at extreme ends to reduce responses due to accidental torsion, therefore, decrease the amplification due to torsional irregularity. It is worthy to note that shear walls are not added exclusively to resist torsional deformations, but as part of careful assessment of system ductility taking into consideration the overall cost.

The dual system in the North-South direction was capable of resisting the seismic forces without additional stiffening and all floors were found to have not torsional irregularities. 
Table 5: Accidental and magnified torsion for seismic forces applied in the East-West direction.

\begin{tabular}{|l|c|c|c|}
\hline Story & $\begin{array}{c}\text { Story drift x story } \\
\text { height } \\
\text { MRSA without } \\
\text { amplified torsion (mm) }\end{array}$ & $\begin{array}{c}\text { Story drift x story } \\
\text { height } \\
\text { MRSA+ amplified } \\
\text { torsion (mm) }\end{array}$ & $\begin{array}{c}\text { Increase in } \\
\text { story drift due } \\
\text { to amplified } \\
\text { torsion }\end{array}$ \\
\hline 13 & 24.53 & 28.644 & $14 \%$ \\
\hline 12 & 27.412 & 33.484 & $18 \%$ \\
\hline 11 & 29.832 & 37.884 & $21 \%$ \\
\hline 10 & 31.878 & 41.756 & $24 \%$ \\
\hline 9 & 33.44 & 44.858 & $25 \%$ \\
\hline 8 & 34.562 & 47.256 & $27 \%$ \\
\hline 7 & 35.31 & 49.038 & $28 \%$ \\
\hline 6 & 35.684 & 50.226 & $29 \%$ \\
\hline 5 & 35.552 & 50.644 & $30 \%$ \\
\hline 4 & 34.518 & 49.896 & $31 \%$ \\
\hline 3 & 31.966 & 47.322 & $32 \%$ \\
\hline 2 & 26.73 & 41.778 & $36 \%$ \\
\hline 1 & 19.844 & 36.57225 & $46 \%$ \\
\hline
\end{tabular}

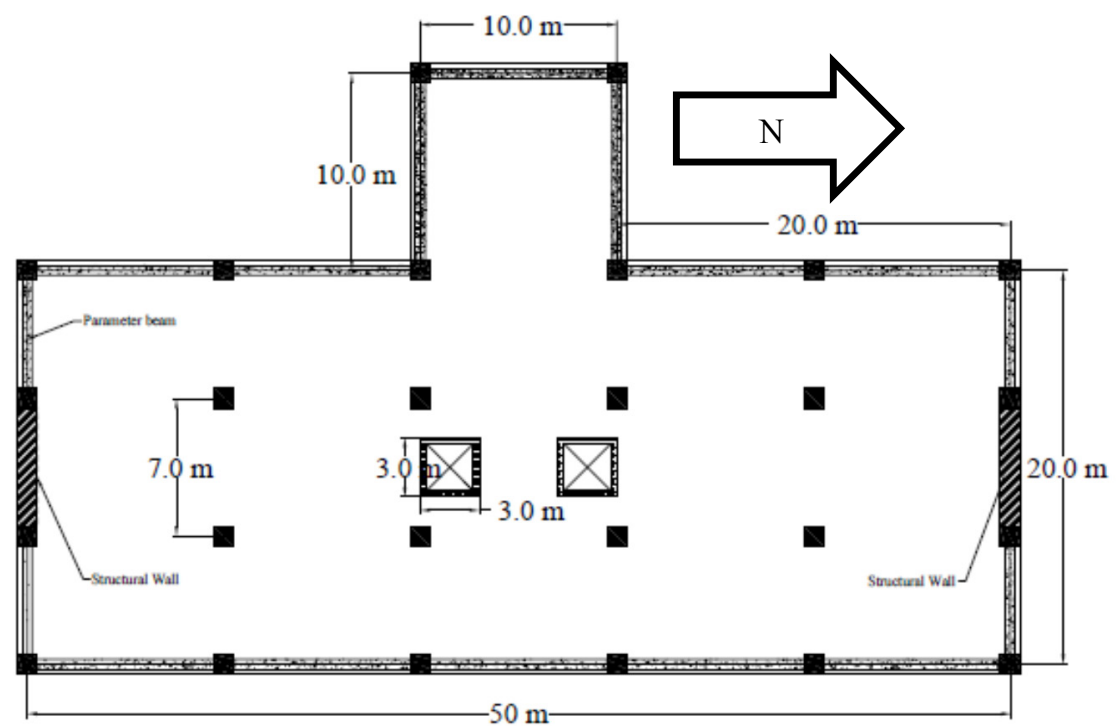

Figure 4: Added shear walls at extreme ends of the floor reduce deformation due to accidental torsion. 
Table 6 shows that after adding shear walls at the extreme ends of the building, lateral deformations dropped significantly.

Table 6: Drift reduction after adding shear walls at extreme ends of a building in the East-West direction.

\begin{tabular}{|c|c|c|c|}
\hline Story & $\begin{array}{c}\text { Lateral structural } \\
\text { drift without } \\
\text { additional shear walls } \\
\text { (mm) }\end{array}$ & $\begin{array}{c}\text { Lateral } \\
\text { structural drift } \\
\text { with shear walls } \\
\text { at extreme ends } \\
\text { (mm) }\end{array}$ & $\begin{array}{c}\text { Percent reduction } \\
\text { in lateral } \\
\text { deformation due } \\
\text { to addition of } \\
\text { shear walls }\end{array}$ \\
\hline 13 & 28.644 & 27.302 & $5 \%$ \\
\hline 12 & 33.484 & 28.71 & $14 \%$ \\
\hline 11 & 37.884 & 29.744 & $21 \%$ \\
\hline 10 & 41.756 & 30.558 & $27 \%$ \\
\hline 9 & 44.858 & 31.042 & $31 \%$ \\
\hline 8 & 47.256 & 31.108 & $34 \%$ \\
\hline 7 & 49.038 & 30.712 & $37 \%$ \\
\hline 6 & 50.226 & 29.788 & $41 \%$ \\
\hline 5 & 50.644 & 28.204 & $44 \%$ \\
\hline 4 & 49.896 & 25.806 & $48 \%$ \\
\hline 3 & 47.322 & 22.352 & $53 \%$ \\
\hline 2 & 41.778 & 17.512 & $68 \%$ \\
\hline 1 & 36.57225 & 12.49325 & \\
\hline
\end{tabular}

\section{Summary}

- Torsional irregularity of building diaphragms or floor systems leads to amplified structural responses including bending moments and drifts and must be accounted for in the computational model to avoid structural failures and building pounding effects.

- The amplification effects caused by torsional irregularity can be accounted for by amplifying the accidental torsion moments applied to the structure.

- It is also possible for many structures to reduce effects of torsional irregularity by careful selection of shear wall locations so that shear walls may provide sufficient resisting moment to counter accidental torsion. 


\section{References}

[1] Minimum Design Loads for Buildings and Other Structures (ASCE/SEI 710); American Society of Civil Engineers; 1801 Alexander Bell Drive Reston, VA 20191, 2010.

[2] Mohamed, O. A. and Khamwan, P., Design of reinforced concrete buildings according to the new NEHRP provisions, Earthquake Resistant Engineering Structures, Wessex Institute of Technology, 2007.

[3] Gokdemir, H., Ozbasaran, H., Dogan, M., Unluoglu, E., and Albayrak, U., Effects of torsional irregularity to structures during earthquakes, Engineering Failure Analysis, Elsevier, pp. 713-717, 2013.

[4] Mohamed, O. A., Variability and Limitations of Seismic Analysis and Modeling Techniques, Proc. Eleventh International Conference on Civil, Structural and Environmental Engineering Computing, doi:10.4203/ ccp.86.213, St. Julians, Malta, 2007.

[5] International Building Code (IBC); International Code Council, $500 \mathrm{New}$ Jersey Avenue, NW 6th Floor, Washington, DC 20001, 2010. 